\title{
Control by an irrelevant stimulus in discrete-trial discrimination learning by pigeons*
}

\author{
VICKY A. GRAY† and N. J. MACKINTOSH \\ Dalhousie University, Halifax, Nova Scotia, Canada
}

Pigeons were trained using a discrete-trial procedure on a discrimination between a tone and white noise, with the key illuminated on all trials with a white vertical line. A control group received the same sequence of trials but a random reinforcement schedule. Generalization gradients (tested in silence) to other orientations of line on the key were reliably flatter in the discrimination group than in the control group. The results confirm other discrete-trial studies in showing that discrimination training suppresses control by an irrelevant stimulus but contrast sharply with the results of similar free-operant experiments.

A series of recent studies by Thomas and his collaborators has shown that discrimination training between two stimuli differing along one dimension may apparently increase the control over responding exercised by an irrelevant stimulus common to both positive and negative trials (Thomas, 1969; Thomas, Freeman, Svinicki, Burr, \& Lyons, 1970). When pigeons were trained in a free-operant situation, with positive and negative trials marked by differences in the wavelength of light projected onto the response key but with a white vertical line appearing on the key on all trials, they subsequently showed a steeper gradient of generalization along the dimension of line orientation than did a control group exposed to the same sequence of stimuli in training but with reinforcement given randomly, irrespective of the wavelength on the key. Similar results were obtained when the common irrelevant stimulus was a particular wavelength and the discriminative stimuli were different orientations of the line, different tilts of the floor of the chamber, or different intensities of an auditory cue. The result has been confirmed by other investigators (e.g., Turner \& Mackintosh, 1972).

Even though the differences reported in one or two of these studies have not been quite significant, the generality of these findings leaves little doubt that the effect is a genuine one. Nevertheless, it remains puzzling, since it stands in sharp contradiction to a set of results reported by Wagner, Logan, Haberlandt, \& Price (1968). In three experiments employing either a discrete-trial discrimination procedure or a classical conditioning procedure, Wagner et al found that discrimination training between two auditory stimuli resulted in a

*This research was supported by Grant APA 259 from the National Research Council of Canada. W. K. Honig sponsors this article and takes full editorial responsibility.

tRequests for reprints should be sent to Vicky A. Gray, who is now at Department of Psychology, University of New Brunswick, Fredericton, N.B., Canada. significant reduction in the control exercised by a light stimulus common to positive and negative trials. Thomas, Burr, \& Eck (1970) have argued that the discrepancy between these results and Thomas's pigeon data is due to a difference in test procedures: Wagner et al simply measured the amount of responding in the presence of the irrelevant stimulus alone, while Thomas, Freeman, Svinicki, Burr, \& Lyons (1970) measured the slope of generalization gradients around the irrelevant stimulus. This account, however, is made somewhat implausible by the demonstration by Turner \& Mackintosh (1972) that if pigeons were trained in a discrete-trial situation and control was assessed by the slope of a generalization gradient, discrimination training decreased rather than increased control by an irrelevant stimulus. The implication is that the critical variable is the use of free-operant or discrete-trial procedures rather than the way of measuring control. Since Turner and Mackintosh's results were obtained using a slightly more complicated design than usual (in which additional training intervened between initial training and final testing) and since the difference between their discrimination and control groups was small, the present experiment was designed to confirm that, when a discrete-trial procedure is used, discrimination training will reduce the amount of control exercised by an irrelevant stimulus.

\section{METHOD}

The Ss were 16 White Carneaux pigeons, approximately 6 months old, maintained at $75 \%$ of their ad lib weights. The apparatus consisted of two standard three-key pigeon chambers with the side keys covered up. The stimuli used were a white line $(2.2 \times 0.3 \mathrm{~cm})$ which was shown vertically $(90 \mathrm{deg})$ during training and at one of five orientations $(30,60,90,120$, or $150 \mathrm{deg})$ during testing. Two auditory stimuli were used: a $1500-\mathrm{Hz}$ tone at $85 \mathrm{~dB}$, produced by a Massey Dickinson click generator, and white noise at $75 \mathrm{~dB}$ from a Grason Stadler noise generator. Automatic programming and recording equipment was located in an adjoining room.

The Ss were initially shaped by hand to peck at the key and then received one session of 40 trials, with each trial starting with the illumination of the key and continuing until $S$ pecked at the key and was reinforced with 5 sec access to grain. Each trial was followed by a variable intertrial interval (average, $24 \mathrm{sec}$, range, 16 to $32 \mathrm{sec}$ ) spent in darkness. A second 40-trial session was given, with each trial being terminated automatically without reinforcement if $S$ failed to peck within $8 \mathrm{sec}$. To facilitate shaping, the key was illuminated with a white vertical line displayed on a blue background, and this condition remained in effect for the first two pretraining sessions. In the remaining two 40-trial pretraining sessions, the white vertical line was shown on a black background and the $1500-\mathrm{Hz}$ tone was turned on at the beginning of each trial.

During training all sessions consisted of 60 trials. On 30 randomly selected trials, the vertical line appeared together with the tone; on the other 30 trials, the vertical line appeared with 


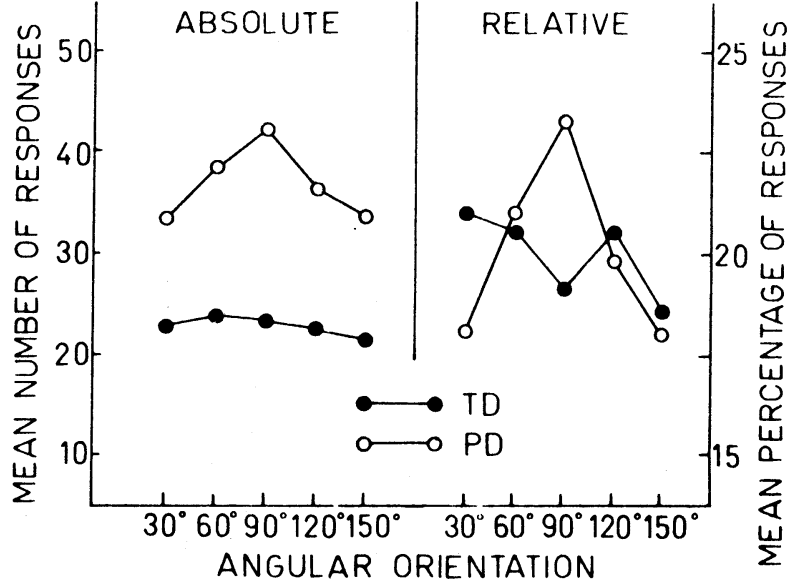

Fig. 1. Absolute and relative generalization gradients from all 3 days of testing.

the white noise. As in the final 3 days of pretraining, all trials were terminated either by a single response or after $8 \mathrm{sec}$ and were followed by an average 24-sec intertrial interval, timed from the end of the 8-sec period during which trial stimuli could be shown. The Ss were divided into two groups of eight. For Group TD (true discrimination), the tone was $S+$ and the white noise S-; for Group PD (pseudodiscrimination), a random half of each kind of trial was reinforced and the remaining trials were not reinforced.

Each TD S was run together with a PD S and, when discrimination training was completed for the TD S, both Ss were tested for generalization to other orientations of the line. The tone-noise discrimination proved relatively difficult. Four pairs of Ss were tested after 20 days of training; the TD members of each pair had all achieved at least 1 day in which they responded on fewer than 10 of the $30 \mathrm{~S}$ - trials presented each day (the mean number of $S$ - responses on Day 20 was eight). The four remaining TD Ss were continuing to average 25 responses to $S$ - per session at this stage, and the remaining pairs were run for 30 days before testing. By this time, two Ss had learned (averaging less than 10 responses to $S$ - per session), one was averaging $20 \mathrm{~S}$ - responses per session, and one continued to respond on all $\mathrm{S}$ - trials.

All Ss received 3 days of generalization testing immediately after the end of training. Each session consisted of 20 presentations of each of five orientations of the line in a random sequence. Neither tone nor noise was presented on any trial and no reinforcements were given. Each trial lasted for $8 \mathrm{sec}$ unless terminated by a response, and the intertrial interval averaged 24 sec.

\section{RESULTS}

Group PD Ss continued to respond on virtually all trials throughout training; Group TD Ss responded on virtually all $\mathrm{S}+$ trials and (with one exception) gradually reduced responding on $S-$ trials.

The combined results of the 3 days of generalization testing are shown in Fig. 1. The left-hand panel shows the absolute gradients, the right-hand panel the relative gradients. From the absolute gradients, it is clear that Group PD both responded more frequently and showed a steeper gradient than Group TD. An analysis of variance confirmed that the overall difference in amount of responding between the two groups was just significant, $F(1,14)=4.60, p=.05$, and that the interaction between groups and stimuli was highly significant, $F(4,56)=4.73, p<.01$.

The relative generalization gradient is obviously steeper after PD training than after TD training. The proportion of responses made to the training stimulus $(90 \mathrm{deg})$ was significantly higher in Group $P D, U=9$, $\mathrm{p}=.007$; indeed, a Friedman two-way analysis of variance showed that, while there were significant differences in the proportion of test responses made to different stimuli in Group PD, $\chi^{2}(4)=21.05, p<.001$, Group TD responded equally to all five stimuli, $\chi^{2}=4.87, p>.20$.

None of these conclusions is affected by the exclusion of the one $S$ in Group TD who failed to inhibit responding to $S-$. This $S$, in fact, responded more frequently during testing than any other $S$ in Group TD and showed the second steepest gradient in the group.

All but one $S$ in Group PD responded on more than 95\% of trials on Day 1 of generalization testing. Their gradients on this day were, therefore, virtually flat, and the inclusion of these scores serves to diminish the difference in gradient slope between the two groups. Figure 2, which shows the absolute gradients obtained on Day 3 of testing, illustrates this point: On this day, Group PD's gradient crosses over with that of Group TD. An analysis of variance on these scores gave a significant interaction between groups and stimuli, $F(4,56)=6.00$, $p<.001$.

\section{DISCUSSION}

The results of this experiment are unequivocal. In a discrete-trial situation, discrimination training reduces the amount of control gained by an irrelevant stimulus present on positive and negative trials, whether such control is measured by the number of responses made to that stimulus in isolation or by the slope of a gradient of generalization around the stimulus. It is important to note that both measures of control agree in showing that the irrelevant stimulus exercised significantly less

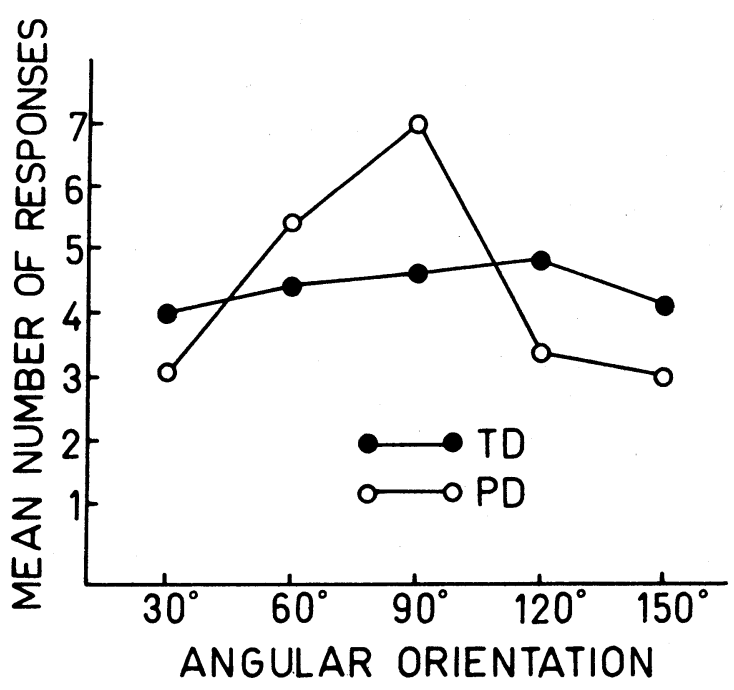

Fig. 2. Absolute generalization gradients from Day 3 of testing. 
control over responding in Group TD than in Group PD. Thus, we can reject the suggestion advanced by Thomas, Burr, \& Eck (1970) that differences in the conclusions reached by different Es are a consequence of their use of different measures of control. The present result confirms that the increase in control by an irrelevant stimulus as a consequence of discrimination training observed by Thomas, Freeman, Svinicki, Burr, \& Lyons (1970) is confined to free-operant situations, and implies that the theoretical analysis provided by Thomas-that discrimination training establishes a general set to attend to all stimulus events-is of less general importance than his data had suggested. Wagner et al (1968) interpreted their own findings as instances of some selective process: Discrimination training, by making one set of stimuli relevant, decreases the control acquired by irrelevant stimuli. As Turner \& Mackintosh (1972) have suggested, it may be possible to reconcile both this theoretical analysis and the discrete-trial data with the data of the free-operant experiments by postulating that, in free-operant situations, there are other uncontrolled irrelevant stimuli (perhaps associated with the repetitive nature of responding in free-operant experiments) and that it is these stimuli which are suppressed by free-operant discrimination training, rather than the explicit irrelevant stimuli manipulated by the $\mathrm{E}$.

\section{REFERENCES}

Thomas, D. R. The use of operant conditioning techniques to investigate perceptual processes in animals. In $R$. M. Gilbert and N. S. Sutherland (Eds.), Animal discrimination learning. London: Academic Press, 1969. Pp. 1-33.

Thomas, D. R., Burr, D. E. S., \& Eck, K. O. Stimulus selection in animal discrimination learning: An alternative interpretation. Journal of Experimental Psychology, 1970, 86, 53-62.

Thomas, D. R., Freeman, F., Svinicki, J. G., Burr, D. E. S., \& Lyons, J. The effects of extra-dimensional training on stimulus generalization. Journal of Experimental Psychology (Monograph), 1970, 83, 1-21.

Turner, C., \& Mackintosh, N. J. Stimulus selection and irrelevant stimuli in discrimination learning by pigeons. Journal of Comparative \& Physiological Psychology, 1972, 78, 1-9.

Wagner, A. R., Logan, F. A., Haberlandt, K., \& Price, T Stimulus selection in animal discrimination learning. Journal of Experimental Psychology, 1968, 76, 171-180.

(Received for publication December 11, 1972.) 